\title{
"The application of the Dyna Sand Filter for Tertiary Treatment in Egypt."
}

\author{
By
}

\begin{abstract}
Aly, O.H.I ${ }^{1}$
1. Assistant Professor of Sanitary \& Environmental Engineering, Higher Institute of Engineering, Shorouk City, Cairo, Egypt.

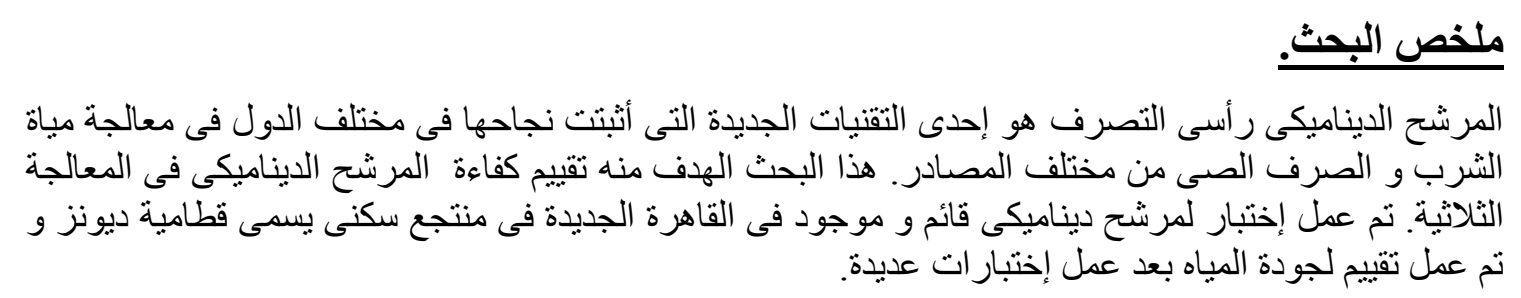

\begin{abstract}
This paper highlights the importance of the use of the dynamic up flow sand filtration system (Dyna Sand) as a new technique successfully applied in different countries for water and wastewater from different sources.

This study was held to evaluate and examine the application of dynamic up flow sand filter to treat waste water, for studying the efficiency of the dynamic up flow sand filter as tertiary treatment. The study was held at Katameya Dunes waste water treatment plant in New Cairo. The study was carried out to examine the performance of the existing Tertiary Filtration Plant. The samples were collected after the secondary treatment of wastewater, before the tertiary treatment. Then the samples examined to prove the success of this filter, where collected after the tertiary treatment by the Dyna Sand. The parameters measured were the BOD, COD and Total Suspended Solids.

The filter showed high removal efficiency in eliminating these parameters. The treatment plant effluent resulted in significant improvement of the bacteriological characteristics of the influent waste water to Katameya Dunes Waste Water Treatment Plant. After Filtration and Chlorination none of these organisms were found, thus the effluent is complying with the ministry of health requirements for reuse of waste water for unrestricted irrigation.
\end{abstract}

\section{Keywords}

Tertiary treatments, Dynamic up flow sand filter, Waste water.

\section{Introduction}

Developing countries suffer from the lack of proper wastewater collection and treatment facilities especially in rural areas. In Egypt more than 95\% of the Egyptian rural areas are not provided with wastewater collection and treatment facilities. There are about 
4,000 Egyptian rural areas with a population ranging from 1,000 to 20,000 capita are suffering from the lack of wastewater treatment facilities.

In general the gap remains remarkable between what is required and what has been attained in that field. Several factors have been responsible for the relatively slow progress rate. The most important one is the escalating cost of providing the needed facilities. Installing centralized wastewater systems is considered an obstacle for the Egyptian government due to high operation, structure and maintenance costs. Accordingly, decentralized treatment can represent a suitable option for the treatment of sewage not only for rural areas, but also for un-served areas with wastewater collection and treatment facilities. As a result the need of medium to small low cost wastewater treatment plants became essential and crucial. The problem can also be described in the difficulty of disposing the polluted water resulting from waste water treatment plants abiding to the environmental laws unless applying complicated and high cost methods such as Thickening, digestion and Mechanical Filtration.

The objective of this research is to examine the performance of an existing tertiary treatment plant. Samples were collected for analysis from the inlet chambers to the filters and from the effluent of the filter before disinfection.

\section{Literature Review}

Tertiary treatment may be defined as any treatment process in which unit operations are added to the flow scheme following conventional secondary treatment. Additions to conventional secondary treatment could be as simple as the addition of a filter for many unit processes for organic, suspended solids, nitrogen and phosphorus removal. Primary and Secondary treatment remove the majority of BOD and suspended solids found in waste waters. However, in an increasing number of cases this level of treatment has proved to be insufficient to protect the receiving waters or to provide reusable water for industrial or domestic recycle. Thus, additional treatment steps have been added to waste water treatment plants to provide for further organic and solids removals or to provide for removal of nutrients and toxic metals. The purpose of tertiary treatment is to provide a final treatment stage to raise the effluent quality before it is discharged to the receiving environment (sea, river, lake, ground, etc...). More than one tertiary treatment process may be used at any treatment plant. If disinfection is practiced, it is always the final process. It is also called effluent polishing. The main purpose can be identified in the additional removal of organic and suspended solids removal, nitrogenous oxygen demand removal, toxic and nutrient removal. We will discuss here the different methods of Tertiary treatment. 


\section{- Filtration}

The Sand Filtration removes much of the residual suspended matter. Filtration over activated carbon, also called carbon adsorption, removes residual toxins. Granular media filtration removes those suspended and colloidal solids, which are carried over from previous unit processes is a common unit process in advanced waste water treatment. Effluents of less than $10 \mathrm{mg} / \mathrm{l}$ BOD and $5 \mathrm{mg} / \mathrm{l}$ suspended solids are not uncommon for effluents from biological treatment processes after filtration. Gravity filters similar to rapid sand filters are sometimes used. Often a combination of filter media, such as anthracite coal and sand are used to provide coarse combination of filter Medias, such as anthracite coal and sand are used to provide coarse to fine filtration as the water passes through the filter. The water passes through the filter media and support gravel and is then collected by the under drain system. As filtration proceeds, the head loss through the filter increase until it reaches an unacceptable level or until solids breakthrough occurs and the effluent becomes unacceptable. When either the head loss becomes excessive or solids break through occurs, the filter is backwashed. Ideally, filters are designed to have the solids in the effluent and the head loss reaches their allowable levels at the same time.

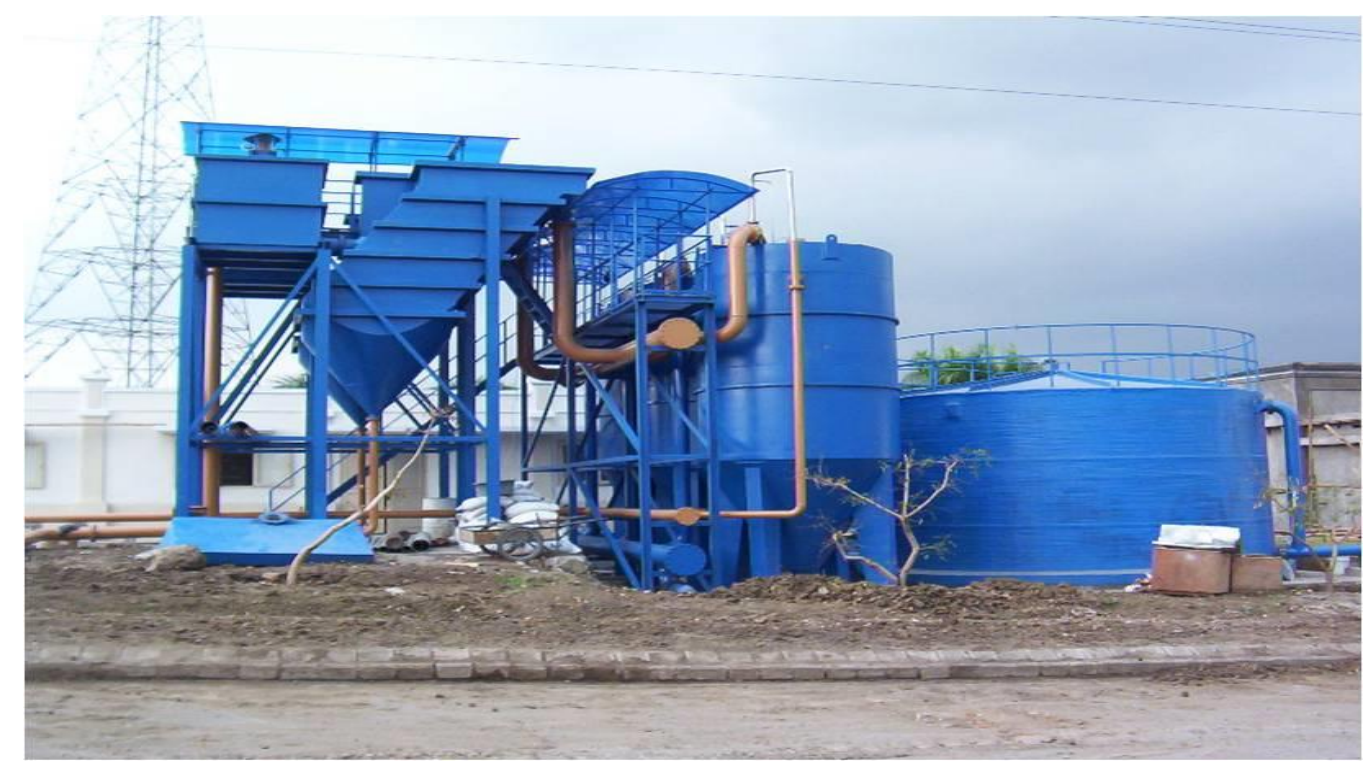

Figure 1: Shows Dyna Sand Plant in Jakarta, Indonesia. 


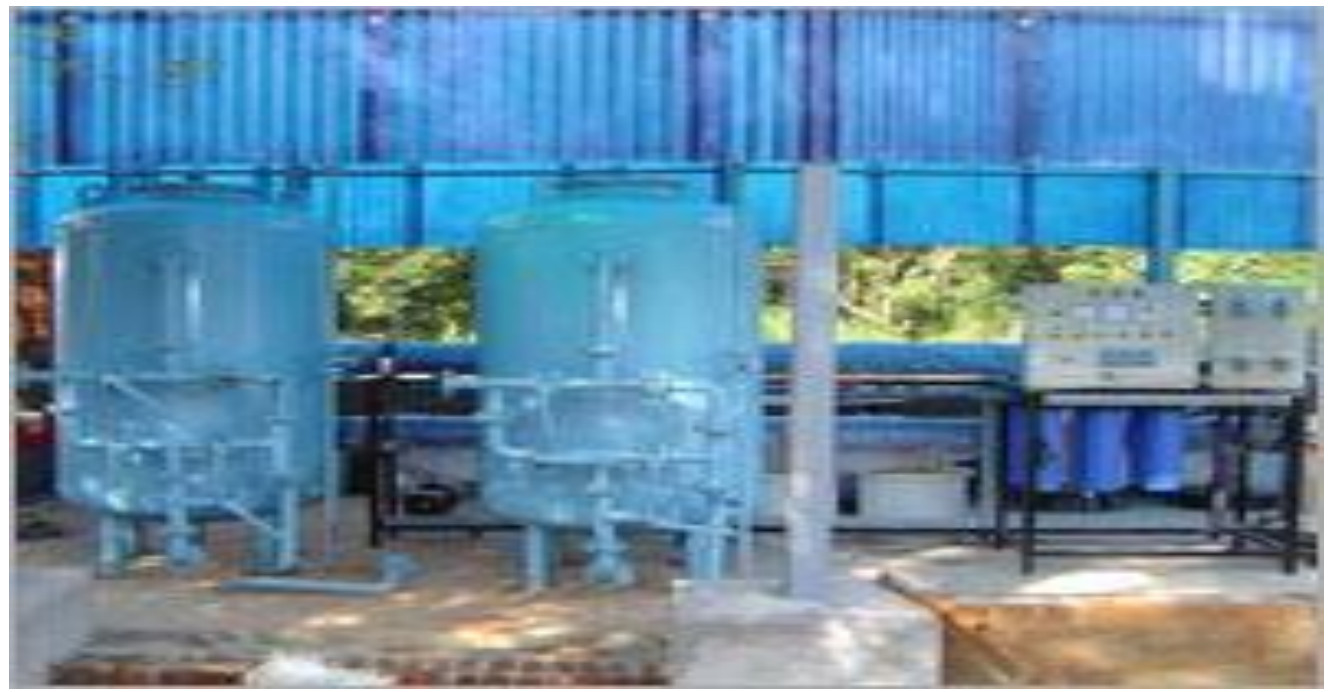

Figure 2: Shows a Tertiary Treatment Plant in Maharashtra, Indonesia.

\section{- LAgOONING}

Lagooning provide settlement and further biological improvement through storage in large man made ponds or lagoons. These lagoons are highly aerobic and colonization by native macrophytes, especially reeds, is often encouraged, small filter feeding invertebrates such as Daphria and species of Rotifer greatly assist in treatment by removing fine particulates.

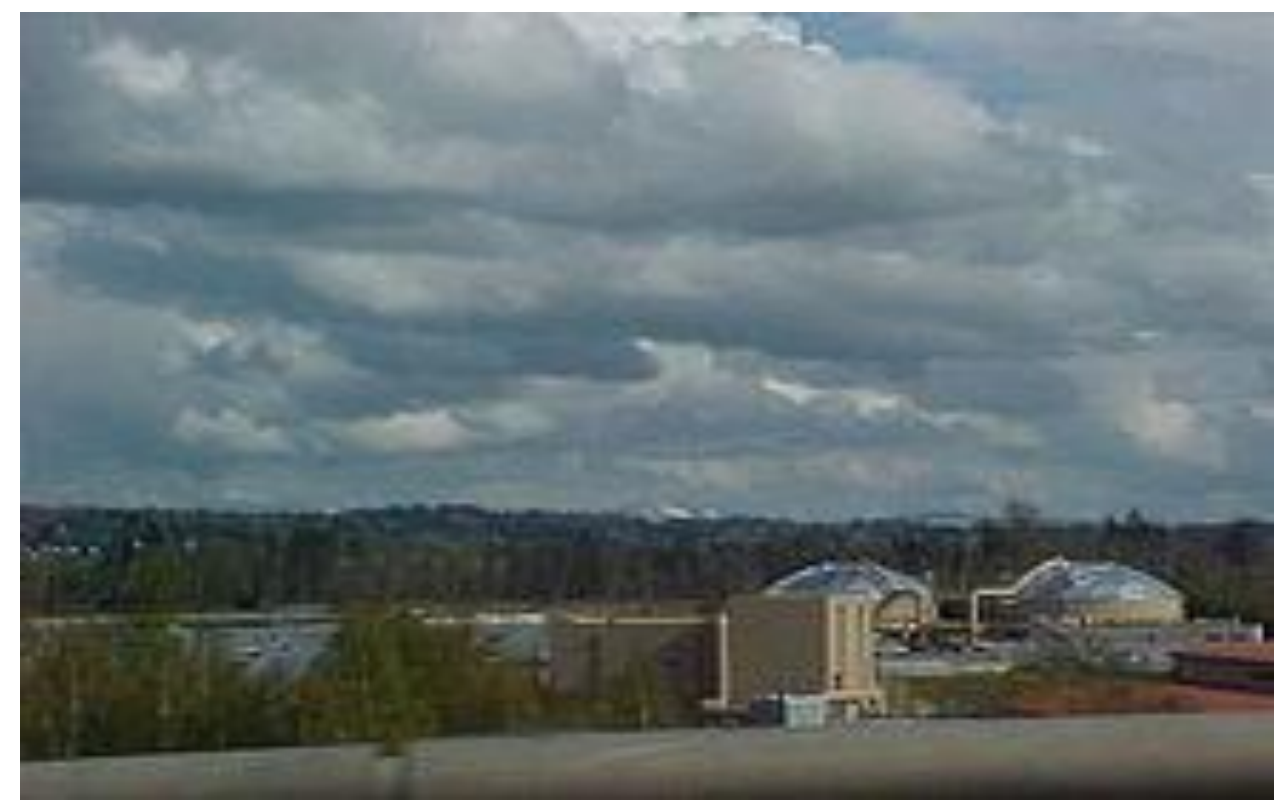

Figure 3: Shows Sewage plant and Lagoon in Everett Washington. 


\section{- Nutrient Removal}

Waste water may contain high levels of the nutrients nitrogen and phosphorus. Excessive release to the environment can lead to a buildup of nutrients, called eutrophication, which in turn can encourage the over growth of weeds, algae, and cyanobacteria (blue green algae). This may cause an algal bloom, a rapid growth in the population of algae, the algae numbers are unsustainable and eventually most of them die. The decomposition of the algae by bacteria uses up so much of oxygen in the water that most or all of the animals die, which creates more organic matter for the bacteria to decompose. In addition to causing deoxygenating, some algal species produce toxins that contaminate drinking water supplies. Different treatment processes are required to remove nitrogen and phosphorus.

The removal of nitrogen is effected through the biological oxidation of nitrogen from ammonia to nitrate (nitrification), followed by de nitrification, the reduction of nitrate to nitrogen gas, Nitrogen gas is released to the atmosphere and thus removed from the water. Nitrification is a two step aerobics process, each step facilitated by a different type of bacteria. The oxidation of ammonia $\left(\mathrm{NH}_{3}\right)$ to nitrite $\left(\mathrm{NO}_{2}{ }^{-}\right)$is most often facilitated by Nitrosamines spp (nitroso referring to the formation of a nitroso functional group). Nitrite oxidation to nitrate $\left(\mathrm{NO}_{3}{ }^{-}\right)$, though traditionally believed to be facilitated by Nitrobacteria spp (nitro referring to the formation of a nitro functional group), is now known to be vacillated in the environment almost exclusively by Nitrospira spp.

De nitrification requires anoxic conditions to encourage the appropriate biological communities to form. It is facilitated by a wide diversity of bacteria. Sand filters Lagooning and reed beds can also be used to reduce nitrogen, but the activated sludge process, if designed well can do the job the most easily. Since de nitrification is the reduction of nitrate to di nitrogen gas. Each person excretes between 200 and 1000 grams of phosphorus annually. Studies of United States sewage in the late 1960s estimated mean per capita contributions of 500 grams in urine and feces, 1000 grams in synthetic detergents, and lesser variable amounts used as corrosion and scale control chemicals in water supplies. Source control via alternative detergent formulations has subsequently reduced the largest contribution, but the content of urine and feces will remain unchanged. Phosphorus removal is important as it is a limiting nutrient for algae growth in many fresh water systems. It is also important for water reuse systems where high phosphorus concentrations may lead to fouling of downstream equipment such as reverse osmosis.

Phosphorus can be removed biologically in a process called enhanced biological phosphorus removal. In this process, a specific bacteria, called polyphosphate accumulating organisms (PAOs), are selectively enriched and accumulate large quantities of phosphorus within their cells (up to 20 percent of their mass). When the biomass enriched in these bacteria is separated from the treated water, these bio solids have a high fertilizer value.

Phosphorus removal can also be achieved by chemical precipitation, usually with salts of iron (ferric chloride, aluminum e.g. alum, lime). This may lead to excessive sludge production as hydroxides precipitates and the added chemicals can be expensive. Chemical phosphorus removal requires significantly smaller equipment than biological removal. Another method for phosphorus removal is to use granular literate. Once 
removed, phosphorus, in the form of a phosphate rich sludge, may be stored in land fill or resold for use in fertilizer.

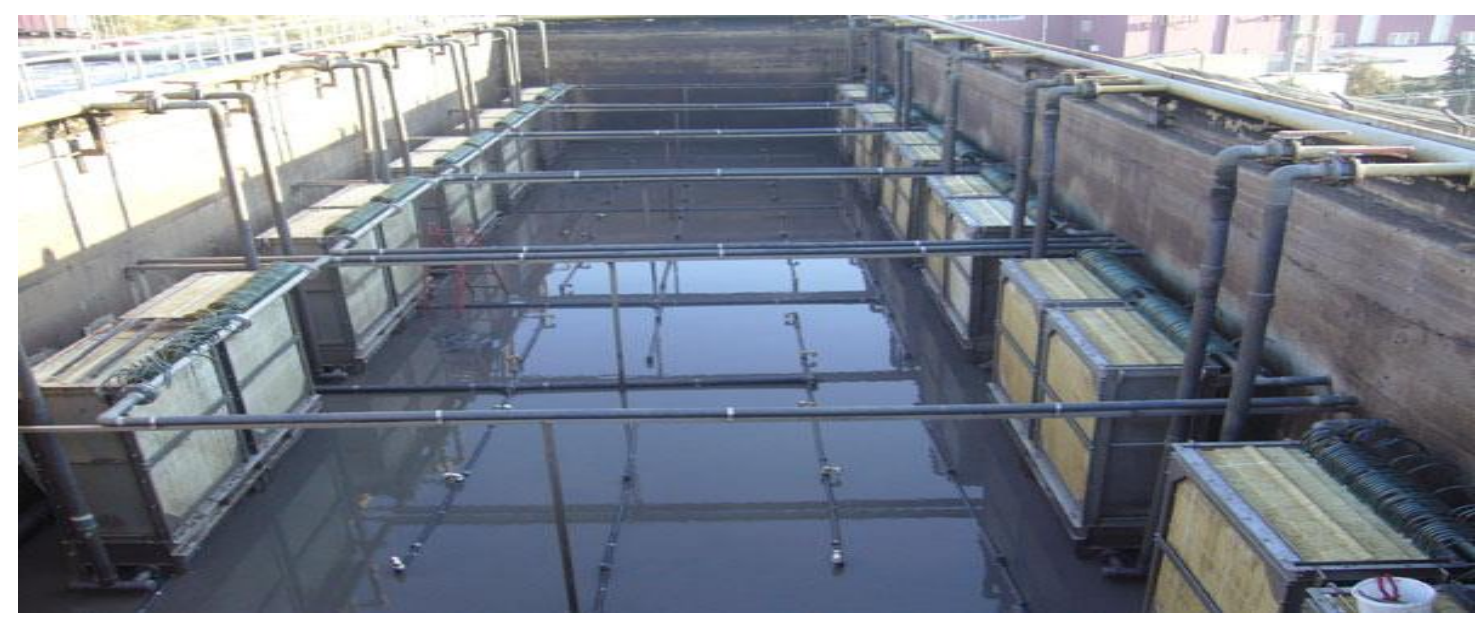

Figure 4: Shows Nitrogen Removal Plant in Romania.

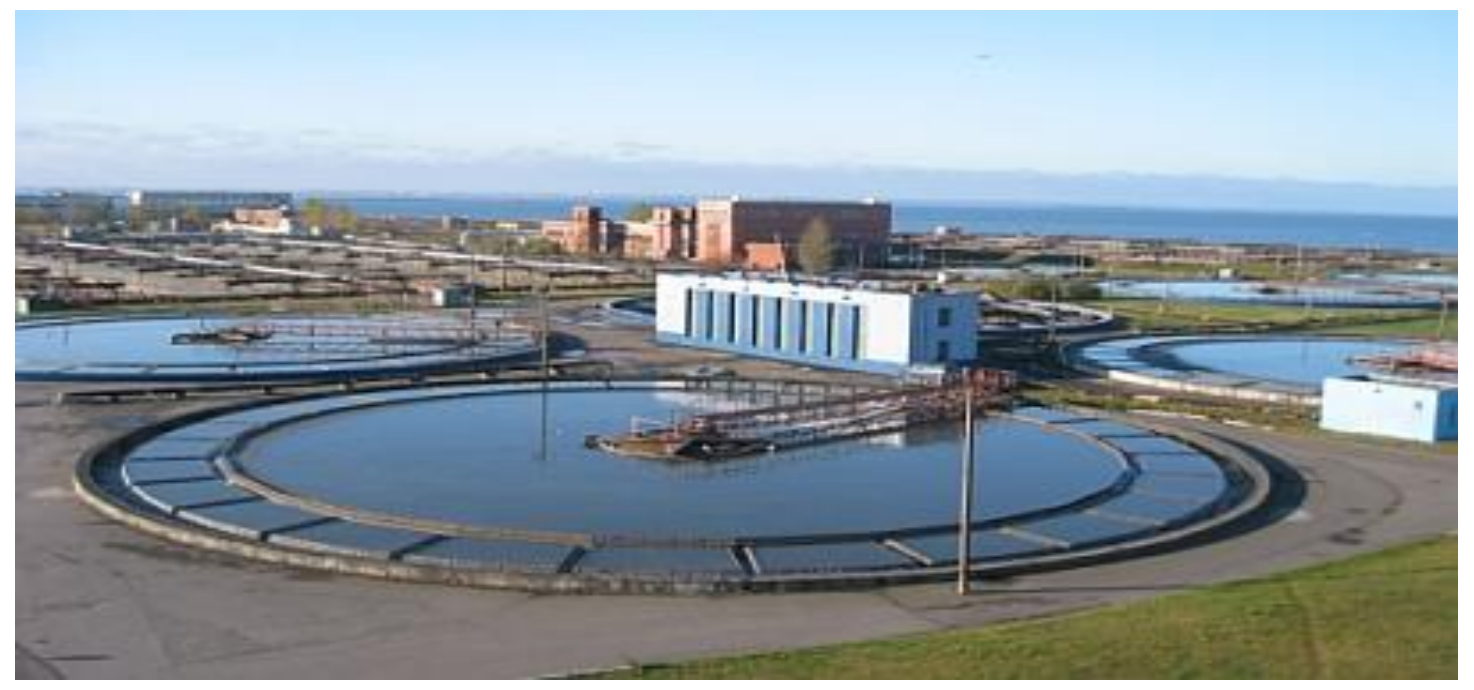

Figure 5: Shows Phosphorus Removal Plant in Russia.

\section{- DISINFECTION}

The purpose of disinfection in the treatment of waste water is to substantially reduce the number of micro organisms in the water to be discharged back into the environment for the later use of drinking, bathing, irrigation, etc. The effectiveness of disinfection depends on the quality of the water being treated (e.g. cloudiness, ph, etc...) and other environmental variables. Cloudy water will be treated less successfully, since solid matter can shield organisms, especially from ultra violet light or if contact times are low. Generally short contact times, low doses and high flows all militate against effective disinfection. Common methods of disinfection include ozone, chloride, ultraviolet light or sodium hypochlorite. Chloramine, which is used for drinking water, is not used in waste water treatment because of its persistence. After multiple steps of 
disinfection, the treated water is ready to be released back into the water cycle by means of the nearest body of water or agriculture. Afterwards, the water can be transferred to reserves for everyday human use.

Chlorination remains the most common form of waste water disinfection in North America due to its low cost and long term history of effectiveness. One disadvantage is that chlorination of residual organic material can generate chlorinated organic compounds that may be carcinogenic or harmful to the environment. Residual chlorine or chloramines may also be capable of chlorinating organic material in the natural aquatic environment. Further, because residual chlorine is toxic to aquatic species, the treated effluent must also be chemically de chlorinated, adding to the complexity and cost treatment.

Ultraviolet (UV) light can be used instead of chlorine, iodine, or other chemicals. Because no chemicals are used, the treated water has no adverse effect on organisms that later consume it, as may be the case with other methods. UV radiation causes damage to the genetic structure of bacteria, viruses, and other pathogens, making them incapable of reproduction. The key disadvantages of UV disinfection are the need for frequent lamp maintenance and replacement and the need for a highly treated effluent to ensure that the target microorganisms are not shielded from the UV radiation (any solids present in the treated effluent may protect microorganisms from the UV light). In the United Kingdom, UV light is becoming the most common means of disinfection because of the concerns about the impacts of chlorine in chlorinating residual organics in the waste water and in chlorinating organics in the receiving water. Some sewage treatment systems in Canada and the US also use UV light for their effluent water disinfection.

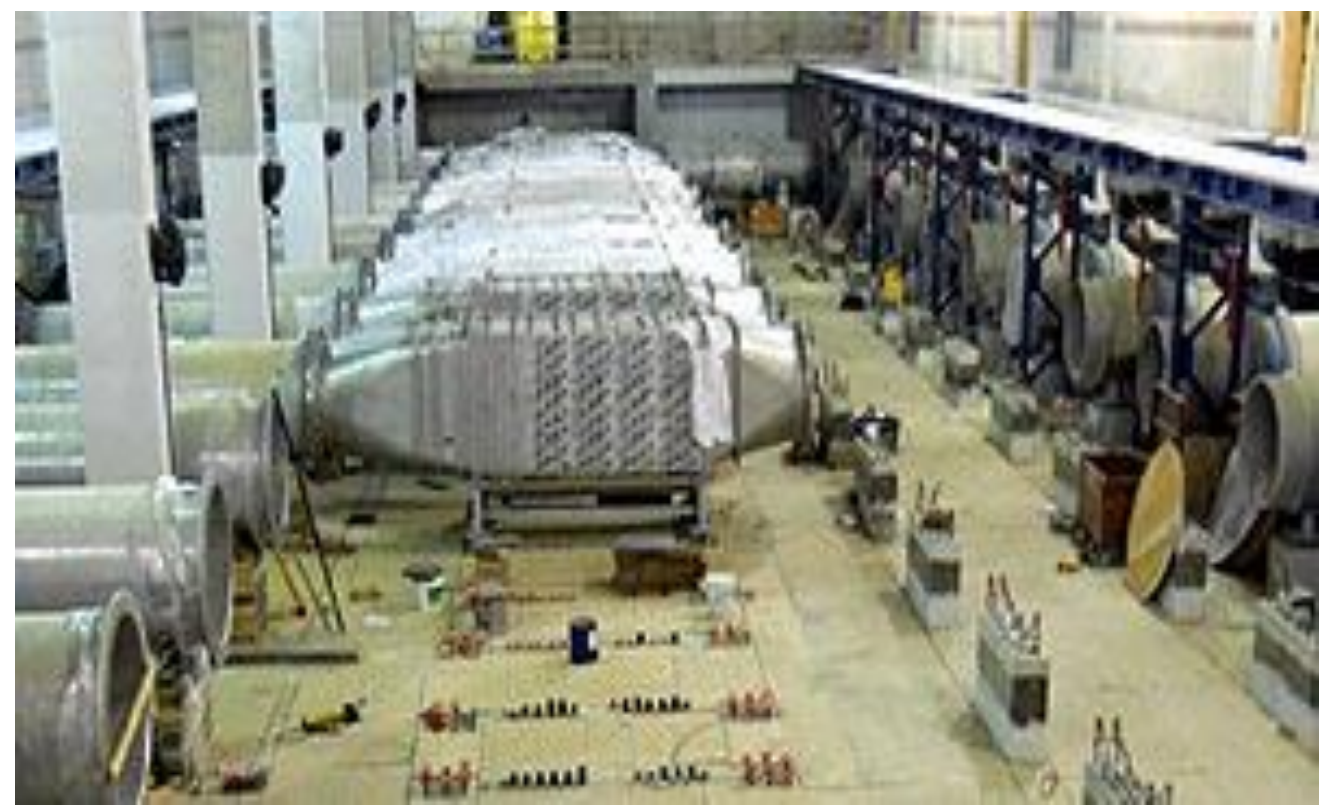

Figure6: Shows UV Plant in New York. 
Ozone $\left(\mathbf{O}_{3}\right)$ is generated by passing oxygen through a high voltage potential resulting in a third oxygen atom becoming attached and forming $\mathbf{O}_{\mathbf{3}}$. Ozone is very unstable and reactive and oxidizes most organic material it comes in contact with, thereby destroying many pathogenic microorganisms. Ozone is considered to be safer than chlorine because, unlike chlorine which has to be stored on site (highly poisonous in the event of an accidental release), ozone is generated onsite as needed. Ozonation also produces less disinfection by products than chlorination. A disadvantage of ozone disinfection is the high cost of the ozone generation equipment and the requirements for special operators.

\section{Materials and Methods}

The pilot unit was installed in a new waste water treatment plant, Katameya dunes, New Cairo for tertiary treatment of secondary effluent received from New Cairo secondary waste water treatment plant. The Katameya Waste Water tertiary treatment is dynamic sand filtration plant, the treatment plant comprise 10 filters divided into 2 groups each of 5 filters. The 2 groups work in parallel or in series. The incoming treated waste water is delivered into an inlet well chamber which provides a water table $1 \mathrm{~m}$ above the dynamic filters. The recovered wash water is also pumped into this inlet chamber. Disinfection of the filtered water is performed by gas chlorination. The Unit of Dyna Sand Filter used is installed in Katameya dunes, New Cairo. The following figure shows the image of the used pilot unit.

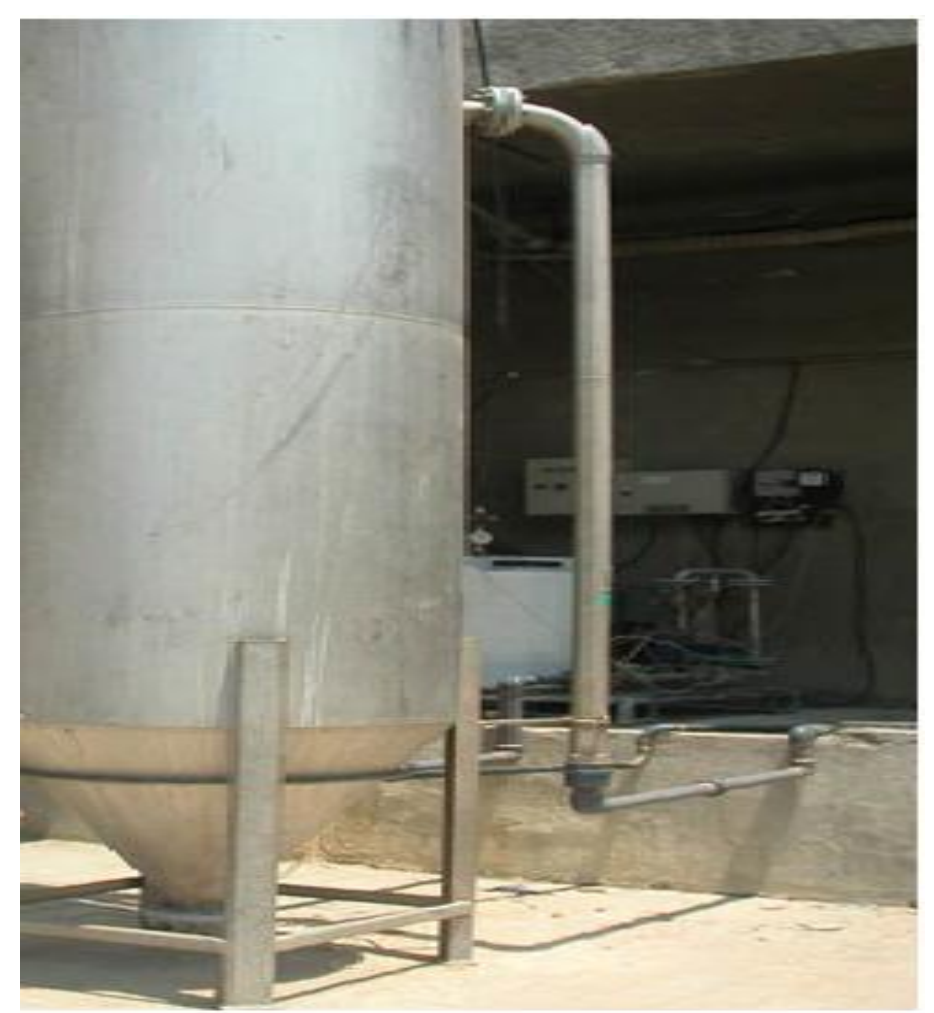

Figure7: Shows Pilot Unit of Dyna Sand. 


\section{Results and Discussion}

The Experiments for the tertiary treatment resulted in the mentioned below results:

- Total suspended solids for the influent waste water was found in the range of 10 to $14.5 \mathrm{mg} / \mathrm{l}$, while for the effluent waste water suspended solids were almost zero.

- The Bio Chemical Oxygen Demand of the influent waste water ranged between 12.5 to $14.5 \mathrm{mg} / \mathrm{l}$, while for the effluent waste water suspended solids ranged between 5.2 to $6.4 \mathrm{mg} / \mathrm{l}$.

- The Chemical Oxygen Demand of the influent waste water ranged between 27 to $30 \mathrm{mg} / \mathrm{l}$, where the corresponding values of the effluent were found to be 10 to $16 \mathrm{mg} / \mathrm{l}$.

The treatment plant effluent resulted in significant improvement of the bacteriological characteristics of the influent waste water to Katameya Dunes Waste Water Treatment Plant. After Filtration and Chlorination none of these organisms were found, thus the effluent is complying with the ministry of health requirements for reuse of waste water for unrestricted irrigation. The Dynamic up Flow Sand Filter can be successfully applied in the treatment of polluted sewage from the wastewater treatment plants; the following bar chart indicates the different parameters measured in case of tertiary treatment and a comparison between the influent and the effluent of the Total Suspended Solids, Chemical Oxygen Demand and the Bio Chemical Oxygen Demand.

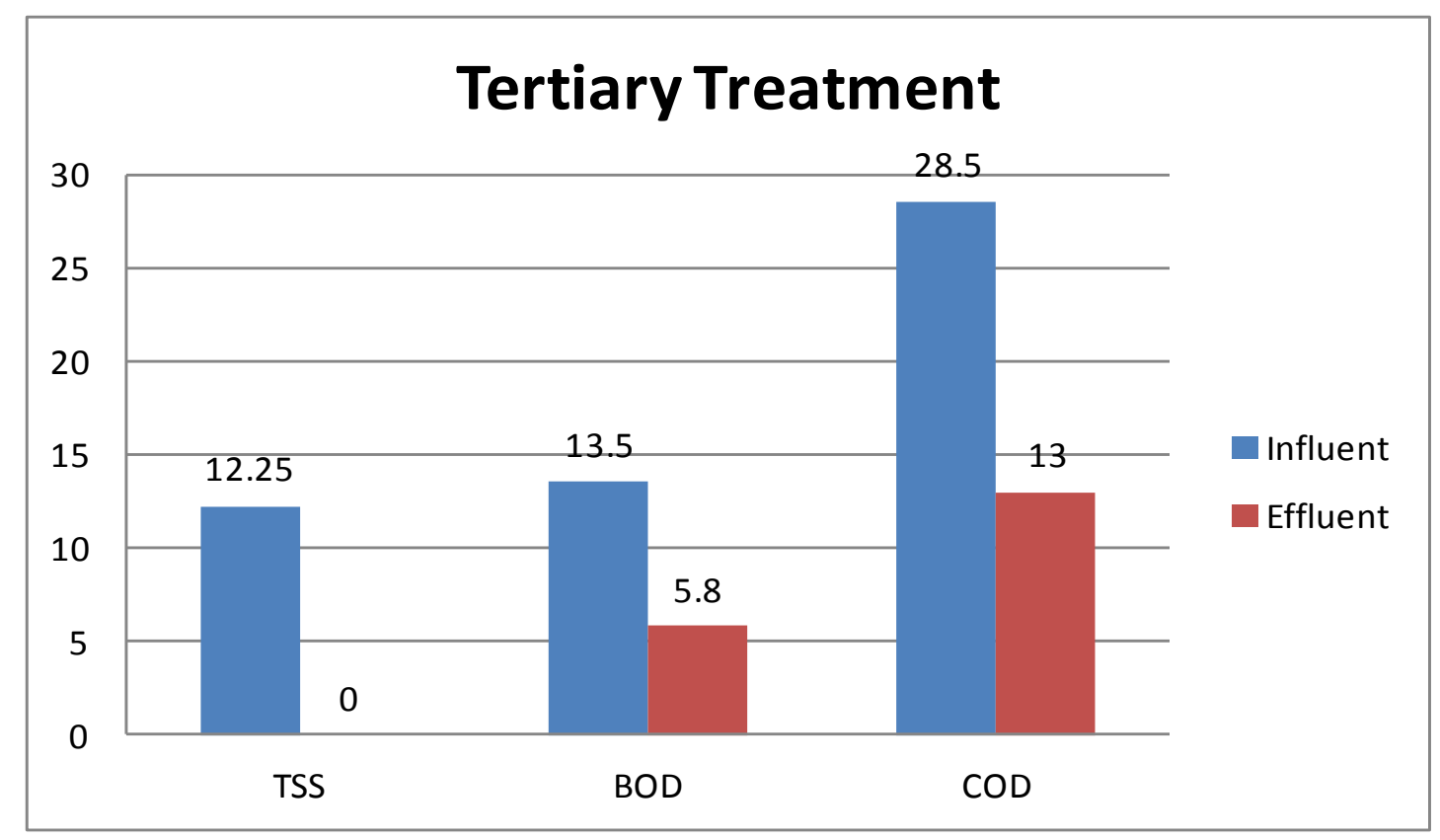

Figure8: The influent and effluent concentration for the different parameters. 


\section{Conclusion and Recommendation}

The conclusions were recorded for Tertiary Treatment as follows:

1. The Total Suspended Solids of the effluent waste water was almost zero.

2. The Biochemical Oxygen Demand of the effluent waste water ranged from 5.2 to $6.4 \mathrm{mg} / \mathrm{l}$.

3. The Chemical Oxygen Demand of the effluent wastewater in the range of 10 to 16 $\mathrm{mg} / \mathrm{l}$.

4. The Treatment plant effluent resulted in significant improvement of the bacteriological characteristics of the influent wastewater to Katameya Dunes Waste Water Treatment Plant, due to the removal of part of the living organisms with the suspended solids.

From the results of this study, it has been proved that the dynamic up flow sand filter is very successful and suitable in the treatment of polluted water from wastewater treatment plants. Therefore, it is recommended to use the dynamic up flow sand filter in:

1. Tertiary treatment of polluted water from wastewater treatment plants to improve the quality of the treated sewage which in return to make it applicable for irrigation, according to the environmental laws.

\section{References}

1. Aly, O.H.I., "APPLICATION OF DYNAMNIC UP FLOW SAND FILTER FOR TREATMENT OF POLLUTED WATER UNDER OPTIMUM CONDITIONS.", Ph. D. Thesis, Faculty of Eng., ASU, Cairo, Egypt, (2011)

2. Abdel Azeem, M.M., "Evaluation of The performance of Dynamic Sand Filtration Under Real Working Conditions.", Sci Bull. Faculty of EngineeringAinShamsUniversity, volume 41, number 4 (December 2006).

3. Ahmed, H. M. H., " Dynasand Filter Application In Water Treatment.", M.Sc. Thesis, Faculty of Eng., ASU, Cairo, Egypt, (2007).

4. Aly, O.H.I., "OPTIMIZATION OF DESIGN AND OPERATING PARAMETERS FOR DYNAMIC UP FLOW SAND FILTER.", M.Sc. Thesis, Faculty of Eng., ASU, Cairo, Egypt, (2009).

5. American water works Association, "State of the Art of Water Filtration." Committee Report. Copy right (1972).

6. Anonymous company,"Continuous Sand Filter", Conference of new techniques in water \& wastewater treatment, Sweden,(1982).

7. Baylis. John R., "Seven Years of High Rate Filtration", Journal American Water Work Association, p. 585 (1956).

8. Conley, W. R. Jr., and Hsiung. K "Design and Application of Multimedia Filters", Journal American Water Works Association, p. 97 (1969).

9. Culbreath. Mark C., "Necessary Modification for High Rate Filtration", Journal American Water Works Association, p. 699 (1968).

10. Culp, R. L., "Filtration", Chapter 8, Water Treatment Plant Design Manual, American Water Works Association, New York, (1969). 